\title{
Environmental Hazards and Women's Health: A Neglected Need
}

\author{
Najmeh Maharlouei (iD ${ }^{1}$ and Hassan Joulaei (iD ${ }^{2,{ }^{*}}$ \\ ${ }^{1}$ Health Policy Research Center, Institute of Health, Shiraz University of Medical Sciences, Shiraz, Iran \\ ${ }^{2}$ Shiraz HIV/AIDS Research Center, Institute of Health, Shiraz University of Medical Sciences, Shiraz, Iran \\ "Corresponding author: Shiraz HIV|AIDS Research Center, Institute of Health, Shiraz University of Medical Sciences, Shiraz, Iran. Email: joulaei_h@yahoo.com
}

Received 2018 December 15; Accepted 2018 December 19.

Keywords: Environmental Hazards, Women's Health, Policy

Environmental health is a set of effects and interactions between humans and their surroundings. The result of these interactions can promote or endanger human health. Accordingly, environmental hazards could be termed as events which threaten the health of inhabitants of that environment either reversible or irreversible (1). Although these hazards comprise pollutants and natural disasters, most of the environmental risks are related to industrial and technological advances that negatively affect the environment and human's health (1).

Generally, man-made hazards can be classified into four categories: Chemical, physical (mechanical), biologi$\mathrm{cal}$, and psychosocial (1). Chemical hazards are those created by chemical substances that can cause significant damages to the environment and ultimately to humans. Some examples are soil pollution and smoking (1). Physical hazards are a kind of occupational hazards, which can be hazardous by contact or non-contact such as noise pollution or X-ray (1). Biological hazards are referred to those biological substances that pose a threat to the health of living organisms, in particular, humans (1). The examples are allergens, infectious epidemics, and food poisoning. The fourth category is psychosocial hazards, which include stress, violence, other stressors, and so on (2).

One of the dimensions of community health promotion is the consideration of environmental mechanisms that affect the individuals' health by ecological effects. Environmental pollutions, including water pollution, air pollution, and noise pollution, reduce health status.

Evidently, the effects of environmental hazards are more severe on women than on men. Not only physiologically, but also socioeconomically are women more vulnerable to environmental hazards. They threaten women from childhood to old age. In wars, the main victims of violence and socioeconomic consequences are women (3).

Research shows that an increase in fine particles in the air exerts negative effects on mental health. The effect of air pollution has been proven on cardiovascular disease, pulmonary diseases such as asthma, stroke, various cancers, and even early death (4). In general, women are less likely to develop heart disease compared to men, but cardiovascular diseases remarkably increase per 10 micrograms of pollutants per square meter of air in diabetic women (5). The concept that housewives who spend most of their time at home are less exposed to the dangers of air pollution is wrong. According to evidence, air pollution creates a major risk for women who are active at home. In fact, two types of air pollution threaten housewives. The first is pollution from outside, as, in large cities, contaminants' levels do not significantly differ inside and outside the house. The second type of pollution is caused by cooking and inhalation of gases from detergents (6). The inhalation of air pollution both inside and outside the house poses a health risk to women. Air pollutants such as suspended particles and heavy metals can reduce the fertility of women (6). On the other hand, women who present in out-of-home work environments, due to the dual responsibility at home and work environment, are more prone to mental harm, and if the risk of sexual violence is added to, their vulnerability will be far greater (7).

The effect of climate change on the health of women and men is different and depends on geographic and socioeconomic factors. Meanwhile, women, especially those in higher poverty, are at a higher risk of climate change effects. Climate change causes women's mortality to increase and their life expectancy to decrease (7). Women and girls are at an increased risk of physical, sexual, and domestic violence after events and disasters. These effects are strengthened by reducing the socio-economic status of women (7).

Despite the fact that women are globally more vulnerable to environmental hazards, government laws have pro-

Copyright ( ) 2018, Women's Health Bulletin. This is an open-access article distributed under the terms of the Creative Commons Attribution-NonCommercial 4.0 International License (http://creativecommons.org/licenses/by-nc/4.0/) which permits copy and redistribute the material just in noncommercial usages, provided the original work is properly cited. 
vided insufficient support for women. To reduce environmental risks, different laws and policies have been developed depending on the country's development to protect the community, but many of them are not by sex, so they are not responsive to women's specific needs.

It is very important to pay attention to the health of women based on their right to be healthy and as a population that comprises half of the society and is responsible for the upbringing of children. In this regard, Iran, in line with international organizations' global plan and like many other countries, needs to design environmental risk reduction policies that meet the different needs of both sexes, while they should be set fairly and in an evidence-based manner. To be more effective, these regulations should engage people and all sectors.

While having distinct programs to control the side effects of environmental hazards in legal and executive aspects, Iran has not yet succeeded to answer many of the society's needs, especially women. Therefore, it needs much more effort at all levels of governance, including people, judiciary, execution, and parliament levels, to give adequate and gender-based responses before and after the appearance of devastating, harmful effects of environmental hazards on the citizens of this land.

\section{Footnotes}

Conflict of Interests: The authors declared no conflict of interests.
Funding/Support: There is no funding support for this study.

\section{References}

1. Chartres N, Bero LA, Norris SL. A review of methods used for hazard identification and risk assessment of environmental hazards. Environ Int. 2018;123:231-9. doi: 10.1016/j.envint.2018.11.060. [PubMed: 30537638].

2. Okeafor CU, Alamina FE. A qualitative study on psychosocial hazards among health care workers in a tertiary health facility in South-South Nigeria. Ann Ib Postgrad Med. 2018;16(1):23-9. [PubMed: 30254555]. [PubMed Central: PMC6143885].

3. Wahlang B. Exposure to persistent organic pollutants: Impact on women's health. Rev Environ Health. 2018;33(4):331-48. doi: 10.1515/reveh-2018-0018. [PubMed: 30110273].

4. Buoli M, Grassi S, Caldiroli A, Carnevali GS, Mucci F, Iodice S, et al. Is there a link between air pollution and mental disorders? Environ Int. 2018;118:154-68. doi: 10.1016/j.envint.2018.05.044. [PubMed: 29883762].

5. Hart JE, Puett RC, Rexrode KM, Albert CM, Laden F. Effect modification of long-term air pollution exposures and the risk of incident cardiovascular disease in us women. J Am Heart Assoc. 2015;4(12). doi: 10.1161/JAHA.115.002301. [PubMed: 26607712]. [PubMed Central: PMC4845261].

6. World Health Organization . Addressing gender inequities in health and environment. Report of the sixth forum on gender and health. 11-12 November 2009; Madrid. 2010.

7. UN Women. Climate change, disasters and gender-based violence in the pacific. 2014. 